\title{
Marx, el cristianismo y la violencia de lo sagrado. Hacia una anamnesis de la teología de la liberación*
}

Fecha de entrega: 28 de octubre de 2018

Fecha de evaluación: 11 de diciembre de 2018

Fecha de aprobación: 30 de enero de 2019

Andrés Felipe Rivera Gómez**

\section{Resumen}

La figura de Karl Marx ha sido vista por algunos católicos como ateísta dada las expresiones tomadas fuera de contexto del pensador de Tréveris. No obstante, con rigurosidad el filósofo Enrique Dussel presenta una imagen muy diferente. Marx en realidad va a ser un crítico de los cristianos burgueses de su época, que confundieron el pensamiento de Jesús con un fetichismo bajo el cual terminaron sacrificando vidas inocentes. De hecho, llegaron a impulsar una violencia de lo sagrado que alcanza incluso hasta nuestros días. Por esta razón es fundamental hacer una relectura del pensamiento marxista desde la teología de la liberación para contribuir a la emancipación del ser humano de todo aquello que lo deshumaniza "en nombre de Dios".

Palabras clave: cristianismo invertido, reino de Dios, fetichismo, alienación, emancipación, humanización.

* El texto hace referencia a las investigaciones del autor en torno a la relación entre el cristianismo y la filosofia. Este artículo refiere el diálogo entre los estudios teológicos y el pensamiento de Marx. Citar como: Rivera Gómez, A. F. (2019). Marx, el cristianismo y la violencia de lo sagrado. Hacia una anamnesis de la teologia de la liberación. Cuadernos de Filosofía Latinoamericana, 40(121), 109-129. DOI: https://doi.org/10.15332/25005375.5473

* Magister en Defensa de los Derechos Humanos y del Derecho Internacional Humanitario ante Organismos, Cortes y Tribunales Internacionales de la Universidad Santo Tomás. Licenciado en Filosofía con énfasis en educación religiosa. Correo electrónico: andresriverag@usantotomas.edu.co 


\section{Marx, Christianity, and the Violence of the Sacred. Towards an Anamnesis of the Theology of Liberation}

\section{Abstract}

Some Catholics have considered Karl Marx to be an atheist, given that they take some of the philosopher's statements out of context. However, philosopher Enrique Dussel presents us with a different image. According to his rigorous study, Marx was a critic of the Christian bourgeoisie of his time, which confused the thought of Jesus with a fetishism that ended up sacrificing innocent lives. In fact, they promoted a violence of the sacred that is still visible in the present. For this reason, it is essential to reread Marxist thought on the basis of the theology of liberation in order to contribute to the emancipation of human beings from everything that dehumanizes them "in the name of God".

Keywords: inverted Christianity, kingdom of God, fetishism, alienation, emancipation, humanization.

\section{Introducción}

Día a día el ser humano tiene que enfrentar diversos sucesos, muchos de ellos dolorosos y que además dejan huellas imborrables que terminan determinando las creencias y la proyección de cada comunidad y cada hombre. En Colombia, por ejemplo, ha sido la violencia, que día a día se incrementa más y paradójicamente — pese a que se conocen sus causas, sus actores y cómo erradicarla- más se mantiene y más arrasa con el sueño de personas que solamente quieren comenzar de nuevo y conocer por un momento cómo sería su realidad si terminara esa guerra sin sentido que no los ha querido soltar.

Tristemente, cada situación actual es un reflejo y una repetición de lo que ya otros han vivido antes, no solo en este país, sino en otras zonas geográficas del mundo entero. Las razones seguirán siendo las mismas: estructuras políticas, económicas, sociales, culturales, religiosas y demás, que lo único que demuestran es lo que podría llamarse pecado estructural. Algo muy parecido a lo que también tuvo que enfrentar el filósofo 
Karl Marx: que las injusticias se mantienen debido a la existencia de gigantes que las crean y una masa que las permite.

Tales razones, entre otras, son las que han llevado a presentar la propuesta contenida en este artículo, la cual busca retomar parte del pensamiento marxista para comprender al filósofo alemán como un crítico de lo que se suele llamar cristianismo invertido (Dussel, 2015, p. 114). Este de alguna manera justificó las estructuras dominantes a partir de ciertas interpretaciones bíblicas, de modo que fue cómplice de una violencia de lo sagrado, es decir, una violencia que se escudaba y se disfrazaba de sagrada al responder que cada sistema dominante era o hacía parte de los designios divinos. Analizar la actitud del pensador prusiano como contraria a ese cristianismo conlleva así mismo dirigirse hacia una anamnesis de la teología de la liberación. Ello en la medida en que es fundamental para el quehacer de una teología de contexto volver la mirada hacia un cristianismo no invertido, sino más bien consecuente con las enseñanzas de su fundador, tal como seguramente el mismo Marx lo percibió (Dussel, 1977, p. 11).

Dado lo anterior, y para desarrollar el propósito de este texto, que emana del título, en un primer momento se presentará una corta biografía y se contextualizará la obra de Marx. En un segundo aparte se desarrollará la idea del cristianismo invertido. Seguidamente se hará hincapié en el tópico del fetichismo y la violencia de lo sagrado. Y se finalizará con el ítem de una anamnesis de la teología de la liberación. Los puntos presentados tendrán fuentes de apoyo como "Sobre la cuestión judía" y "Para una crítica de la filosofía del derecho de Hegel” del propio Marx; una conferencia realizada por Enrique Dussel en 2017 en la Unam, titulada: “Diálogo interreligioso", y el texto Las metáforas teológicas de Marx, también de Dussel.

\section{Biografía de Marx y contexto de su filosofía}

De Marx se ha tenido conocimiento en parte por las lecturas que otros han hecho de él, razón por la cual en sectores religiosos ultraconservadores lo han tenido como uno de los filósofos de la sospecha e incluso como un ateo debido a ciertas afirmaciones que, sacadas de contexto, no dejan menos que preguntarse por la opinión del pensador prusiano con respecto a la fe. No obstante, después de haber leído algunos apartes e igualmente escuchado la lectura y el punto de vista del pensador Enrique Dussel se puede contemplar que Marx, tal vez, no de manera consciente o directa, tenía incluso la misma idea que tenía Jesús sobre Dios, “Un ser realmente liberador”, totalmente 
opuesto al que predicaban los fariseos del ala ultraortodoxa, lo que lleva a pensar que por las dinámicas religiosas del tiempo de Jesús este seguramente fue acusado cuando menos de hereje en su momento. Ahora bien, es necesario, para justificar las afirmaciones hechas, conocer un poco de la vida y el contexto del filósofo de Tréveris.

Alemania según la historia fue prácticamente la cuna del protestantismo. No obstante, allí también se mantuvo el cristianismo católico. Y ambas prácticas tuvieron que vérselas con el judaísmo debido a la llegada constante de migrantes de ascendencia semita. En ese sentido, sostiene Dussel en su texto Las metáforas teológicas de Marx:

Marx nace el 5 de mayo de 1818 en Tréveris, ciudad alemana de origen romano y de larga historia medieval, de una familia paterna judía (llamada Marx-Levi) de antigua tradición rabínica — desde el siglo xv hay rabinos Marx-Levi, y fueron rabinos de Tréveris su abuelo y uno de sus tíos, Samuel Marx, en vida del mismo Marx-. Por motivos políticos, ya que el emperador prusiano deseaba una burocracia homogénea, su padre es obligado a bautizarse luterano, entre 1816 y 1817 . El 26 de agosto de 1824 hace lo propio Marx; su madre nunca deseó bautizarse y se mantuvo espiritualmente judía.

Parece, sin embargo, que Marx no conoció el hebreo. Como su padre, fue Marx de origen pequeñoburgués, de formación en la tradición judía, luterana con influencias pietistas y dentro de la cultura de la Ilustración. (Dussel, 1993, p. 25)

Narra también Dussel que Marx inicialmente asistió en Tréveris al gimnasio católico, donde estudió de 1830 a 1835. Dentro de este periodo de formación uno de sus profesores fue Johann Abraham Küpper, cuya teología moral cristocéntrica y trinitaria influyó poderosamente en el joven Marx.

Dentro del protestantismo alemán se había introducido a su vez una tendencia pelagiana contra la que ya había tenido que luchar Agustín. Para dicha doctrina la salvación se daba por un esfuerzo personal, no era gratuita y ni siquiera necesaria. Más aún, el pelagianismo negaba el pecado original. El teólogo africano, por el contrario, afirmaba que la gracia sobrevenía directamente de Dios, estaba por encima del pecado y, por ende, borraba el pecado original. 
Igualmente, surgió en Alemania una práctica conocida como pietismo, que conservando algo del pelagianismo buscaba que la fe y la piedad del creyente no fuesen algo meramente abstracto y elevado, sino, por el contrario, algo materializable en una praxis. De ahí que su tema de meditación central fuera la vida misma:

El joven que inicia su carrera en la vida [...]. Lo que queremos ser en la vida [...]. Por un puesto en la vida [...]. Lo más alto que la vida pueda ofrecernos [...]. La trayectoria de la vida [...]. No siempre podemos escoger en la vida [...]. Hermosos hechos de la vida [...]. En vez de entrelazarse con la vida, se alimentan de verdades abstractas [...]. Si somos capaces de sacrificar la vida (das Leben [...] zu opfern), (Dussel, 1993, p. 31)

También se encuentra otra marca en el joven Marx que evidencia ese mismo pietismo y tiene que ver directamente con un tema particular: la comunidad (Gemeinschaft). Se trata de la imagen de esta tal cual la describe el libro de los Hechos de los Apóstoles, que el pensador alemán usará para apuntalar más adelante su idea socialista:

Amaría también a los otros sarmientos porque un jardinero les cuida y una raíz les da fuerza. Por eso, la unión con Cristo, desde lo profundo y desde la más viva comunidad (Lebendigsten Gemeinschaft) con él, consiste en que le tenemos en el corazón y ante los ojos; mientras nos sentimos poseídos del mayor amor a él, dirigimos nuestro corazón simultáneamente hacia nuestros hermanos que él une a nosotros. (Dussel, 1993, p. 31)

Tales afirmaciones dejan en evidencia la que va a ser una de las tesis centrales del pensador de Tréveris: el concepto de comunidad está relacionado directamente con la vida, la esencia de esta y la existencia misma. Se debe materializar en algo parecido a la primera comunidad cristiana, donde aún nada estaba invertido y las personas hacían parte de un todo, pero sin alienarse convirtiéndose en medio, a diferencia de lo que Marx descubrió que ocurría en su época (Romero, 2005, p. 119).

Marx de seguro requirió mucha valentía para publicar lo que escribió y exponer lo que pensaba pues no era fácil defender su postura ante el contexto enfrentado desde su juventud. Alemania había sido la cuna y el centro del protestantismo en medio de un cristianismo católico que se mantuvo pese a los diferentes cambios y a la posición de algunos príncipes. Tal ambiente provocó una serie de guerras religiosas que poco a 
poco se fueron apaciguando a través de algunos pactos de paz en la región. Conforme cada movimiento o grupo se iba comprometiendo a cesar la violencia mediante algún acuerdo, más y más personas estimaban importante difundir sus creencias y sus prácticas con el fin de mantener un estilo de vida defendido incluso por los mismos príncipes y demás gobernantes. Wurtemberg, ducado de Alemania, va a tener una fuerte influencia pietista, que incidirá a su vez en Hegel y Marx, quienes en primera instancia tendrán que enfrentarse al luteranismo hegemónico que impera allí. El pietismo de hecho había surgido por la necesidad de renovar aquel luteranismo encaprichado con el poder.

Karl Alexander fue un duque católico considerado por el movimiento pietista como un "anticristo" debido a la corrupción a la que había llevado a la región. Sus abusos y su mal testimonio de vida hicieron que dicho movimiento reaccionara invocando la consecución del Reino de Dios, pero ya no lejano ni abstracto, sino más bien cercano a la realidad de todos. Esto era totalmente contrario a lo que proponían los luteranos hegemónicos, que justificaban constantemente el dominio de los poderosos por encima de los pobres y oprimidos. Tal rama del luteranismo, que tendrá sitio tanto en Holanda como en Inglaterra, fue la que precisamente rechazó Marx (Weber, 1991, p. 11).

El pietismo alemán va a ser el contrapeso de ese otro cristianismo que poco a poco había ganado lugar entre los poderosos, pero que cada vez se alejaba más del verdadero mensaje del Evangelio. Philipp Jacob Spener (1635-1705), su creador, predicaba la necesidad de demostrar con hechos aquello que se profesaba como fe. Ahora bien, esa idea de llevar las creencias a la praxis seguramente surgió de retomar el modelo de la comunidad primitiva que se presenta precisamente en los Hechos de los Apóstoles. De ahí también el interés de Marx de poner a la comunidad como centro y realización de todo hombre. Igualmente, el filósofo alemán va a tener presente el "principio pietista [de] que no lleva la naturaleza la culpa o el mérito, sino que es el hombre mismo autor de ello" (Dussel, 1993, p. 10).

Además de ese cristianismo hegemónico manifestado tanto en los luteranos ortodoxos como en el duque católico, Marx tendrá que vérselas con los inmigrantes judíos en Alemania debido a que ellos van a justificar sus estructuras de poder en lo que el filósofo alemán termina llamando "fetiche", una representación de Dios mediante una imagen totalmente ajena a lo que realmente Él es. Por eso el filósofo de Tréveris 
reconocerá que lo que se está apoderando del mundo en su época es producto de un cristianismo invertido, tema del siguiente acápite.

\section{El cristianismo invertido}

El cristianismo que contempla Marx desde el inicio es el que se refleja, como ya hemos dicho, en los Hechos de los Apóstoles, que narran una vida en comunidad en la cual todo es compartido, unos se preocupan por el bienestar de otros, cada quien se abre a la realidad y la necesidad de los demás y no existe la indigencia porque todos se dan la mano y se bastan a sí mismos. Ciertamente el mensaje del Maestro de Nazareth había quedado en los corazones de todos: "Quien quiera ser el primero, que se haga servidor de todos" (Mc 10:43). Por tal razón, los pietistas tenían presente que el verdadero cristianismo, tal como lo predicó Jesucristo, es aquel que invita al servicio por los demás y no a buscar ser servidos.

En ese sentido, Dussel describe así la perspectiva pietista del estilo de vida primitivo cristiano:

Una comunidad ética bajo la legislación moral divina es una iglesia que, en cuanto que no es ningún objeto de una experiencia posible, se llama la iglesia invisible... La visible es la efectiva unión de los hombres en un todo que concuerda con aquel ideal. (Dussel, 1993, p. 11)

En una conferencia llevada a cabo en la Unam a mediados de 2017 Dussel sostiene que Marx no atacaba al cristianismo de los primeros siglos, sino que su adversario era lo que hoy se puede denominar cristianismo invertido (Dussel, 2017). Dicho nombre denuncia la tergiversación del mensaje predicado por Jesucristo y puesto en práctica por los primeros cristianos. La doctrina así bautizada justifica una estructura de poder que ocasiona al mismo tiempo un pecado estructural y una lectura descontextualizada, literalista y dominionista del texto sagrado (Spadaro, 2017). Su objetivo es validar acciones que terminan pasando incluso por encima de la dignidad y los derechos humanos del otro.

Sostiene el filósofo argentino que la primera inversión del cristianismo se dio con Constantino el Grande: los cristianos eran perseguidos, pero una vez acogida su fe como la religión oficial del Imperio, tras la publicación del Edicto de Milán, se 
convirtieron en los perseguidores. Otra inversión tuvo ocasión en la Edad Media, durante las cruzadas: nuevamente el cristianismo se invierte y Tierra Santa es el epicentro de saqueos, muertes y afrentas en nombre del "Hijo de Dios".

La tercera inversión se da antes de la caída del Imperio bizantino, cuando el cristianismo se convierte en una religión de metrópolis y se sigue expandiendo a pesar de las incursiones musulmanas a territorio bizantino, emprendidas por diversas facciones que buscan establecer diferentes vías de comercialización con Occidente. Esta última inversión mostró que ya no se podía hablar del cristianismo como esa experiencia de los primeros cristianos, sino como cristiandad, toda una cultura que incluía un arte y una manera de vivir y de ser lejanas a lo que se dio en los primeros siglos después de Cristo (Dussel, 2017).

Otra inversión más se relaciona con la conquista española en territorio americano. Después de encontrarse en un ambiente metropolitano y haberse reconocido como cristiandad el cristianismo se volvió colonizador, con lo cual mostró la inversión definitiva del ser cristiano. Se le llama igualmente "invertido" porque se da un antagonismo entre el mensaje de Jesús y su interpretación teoconservadora, que pretende justificar cualquier comportamiento para mantener un poder temporal sustentado en el espiritual. Debe decirse que la inversión se da de la misma manera al mantener la visión neoplatónica de Agustín, según la cual el mundo está separado por dos poderes, uno espiritual, que aquel refiere a la Ciudad de Dios, y otro temporal, supeditado al primero: pese a esta prescripción, históricamente la cristiandad nunca fue fiel a ese ideal pues el poder temporal siempre se impuso.

El cristianismo puro y transparente, que resalta la dignidad humana por encima de todo, tal cual lo defendía su fundador se va a apartar, fruto de tal inversión, del que se va a conocer como Estado cristiano. Es a este último al que Marx criticará en su texto "Sobre la cuestión judía" así:

El Estado cristiano - como lo llaman- que reconoce el cristianismo como su fundamento, su religión oficial y por tanto excluye las otras religiones, no es el Estado cristiano acabado, sino que lo es sólo el Estado ateo, democrático, el Estado que asigna a la religión su puesto entre los otros elementos de la sociedad burguesa. (Marx, 2012c, p. 24) 
Y más adelante continúa: "El que llaman Estado cristiano es el Estado imperfecto y la religión cristiana le sirve como complemento y para santificar su imperfección" (2012c, p. 25). Así mismo Marx va a juzgar el Estado que él conocía muy bien y se había instaurado en Alemania tomando al cristianismo como peso que lo soportaría:

El Estado democrático, el Estado real, no necesita de la religión para ser políticamente completo. Por el contrario, puede hacer abstracción de la religión, porque en él el fondo humano de la realidad se realiza de manera profana. En cambio, el Estado llamado cristiano se comporta políticamente con la religión y religiosamente con la política. Una vez que degrada las formas políticas a una apariencia, hace lo mismo con la religión. (2012c, p. 25)

Afirmaciones como esas podrían hacer pensar que el prusiano está dirigiendo su ataque contra la religión cristiana misma. No obstante, la crítica no va hacia el cristianismo en sí, sino a la forma como el Estado había asumido un vínculo con aquel con el único fin de apuntalar su poder. Motivo que lleva a Dussel a vislumbrar un rechazo más bien de esa inversión del cristianismo en la política y no de la religión en sí.

Sostiene el filósofo alemán: "En el Estado cristiano-germánico el poder de la religión es la religión del poder” (Marx, 2012c, p. 26). Se reafirma así el conocimiento de la inversión de la que venimos hablando: Marx sabe que el cristianismo ha abandonado su esencia, el servicio a los demás, para usar a estos últimos como mera justificación de un sistema dominante. Mantener una estructura así implica esclavizar, pero no de cualquier manera, sino sutilmente, para evitar descubrir el plan macabro. Tiene que manejarse un lenguaje persuasivo, que oculte la injusticia de dichas relaciones basadas en el dominio haciéndolas parte de un designio divino. Incluso tomando de manera literal algún fragmento del texto sagrado se puede hacer creer que la organización social que vende el Estado es "divina” porque a unos Dios les dio cierta potestad y gobierno y a otros, la capacidad de obedecer para mantener ese supuesto "orden establecido" (Casabó, 2007).

Lo anterior se infiere precisamente de la siguiente afirmación del pensador de Tréveris:

En el llamado Estado cristiano se halla vigente la enajenación, no el hombre.

El único hombre válido, el rey, no solo es específicamente distinto de los otros 
hombres, sino un ser religioso en sí mismo, unido directamente con el cielo, con

Dios. Las relaciones dominantes siguen basándose en la fe. (Marx, 2012c, p. 27)

Sostiene entonces Dussel de Marx:

Y de ahí que la crítica está en el perfecto derecho que obliga al Estado cristiano, que invoca la Biblia, a reconocer lo torcido de su conciencia desde el momento que la vileza de sus fines seculares, cuando trata de encubrirlos con el manto de la religión, se halla en flagrante contradicción con la pureza de su conciencia religiosa.

Aquellos que, en nombre del evangelio, lo invierten porque no se dan cuenta que están generando pobreza. La propia estructura de su modelo económico, porque toman la Biblia para decir que la obtención de la riqueza es una obtención de Dios, tal como lo pensó el calvinismo. (Dussel, 1993)

Enrique Dussel percibe que la crítica marxista cada vez va siendo más aguda debido a que identifica en el Estado cristiano, que se había instaurado tanto en Alemania como Holanda e Inglaterra, no solamente la inversión del cristianismo, sino las consecuencias de esta: el empobrecimiento de las personas, la enajenación de sus derechos y la imposibilidad de la mayoría de emanciparse ante una situación opresora, sin oportunidades de realización personal, que no puede estar separada de un fortalecimiento de la comunidad. Va a ser precisamente esa inversión del cristianismo la que justificará el fetichismo como medio de alienación del ser humano. El pretexto será la concepción de un Dios que admite una fractura social en función de la legitimación de un poder. Ese el siguiente tema que consideraremos.

\section{El fetichismo y la violencia de lo sagrado}

Marx rechaza lo que va a denominar fetiche: una creación humana, un objeto que termina convirtiéndose en divinidad y ente sagrado que resguardará una estructura opresiva, producto de la ya mencionada inversión del cristianismo (Cueva, 1984, p. 32). Es ese fetichismo el que generará una violencia de lo sagrado tras enajenar a los seres humanos, a quienes oprime bajo un yugo dominador, haciendo ver tras una figura una supuesta intervención divina. Dicha estrategia permite seguir sustentando 
la acción dominadora y de yugo atado al cuello de los que siempre llevarán las de perder, los pobres; o mejor, en palabras de Marx, el proletariado.

El crítico y pensador de Tréveris reconoció que el mundo occidental se estaba cimentando sobre el capital, lo que daba apertura a un entorno netamente capitalista. Esto llevó al joven Marx a comprender que tal capital era la representación misma de los dioses de hechura humana que habían tenido que enfrentar los profetas del Antiguo Testamento. Entre esos falsos dioses, como los llamaran los profetas, se cuenta Moloch/ Baal, el dios fenicio que rondó la vida del pueblo de Israel una vez restablecido en la tierra de Canaán. Dussel, en su texto "Metáforas teológicas de Marx”, argumenta al respecto:

Si se acepta (por ahora sin demostración) que el capital es el "Moloch", el "fetiche", el "demonio visible", como desarrollo de la doctrina del Anticristo del joaquinismo pietista, el cristiano se encontraría en una contradicción clara, porque el ejercicio cotidiano de la praxis en el sistema capitalista involucraría éticamente una acción satánica demoníaca. Si esto fuera así, el tal cristiano podría evadir dicha contradicción de cuatro maneras: o 1) afirmando su cristianismo y renunciando al ejercicio del capitalismo (que es lo que intentaba Marx); o 2) afirmando el capitalismo y renunciando al cristianismo (que acontecía y acontece con poca frecuencia); o 3) inventando una religión fetichista, con el nombre de cristiana, modificada de tal manera que no fuera contradictoria con el capital (y de ahí la producción, por ejemplo, del puritanismo holandés o inglés, de una actitud religiosa que el capital necesita para su reproducción con "buena conciencia"); o, por último, 4) interpretando de tal manera al capital (y esta es la función de la economía política capitalista de Smith, Ricardo, Malthus, etcétera, ocultando la no-eticidad esencial del capital) a fin de que no aparezca como contradictorio al cristianismo más auténtico y profético. (Dussel, 1993, p. 15)

El fetiche se relaciona así con ese dios pagano característicamente dominador y propio de los poderosos. Todo lo contrario al Dios liberador. Como dios dominante el fetiche exige siempre un sacrificio, el cual recae sobre las personas que deben someterse a él. Esto muestra claramente cómo se puede caer en una violencia de lo sagrado: Moloch necesita de víctimas para poder ser (Strom, 2019); las víctimas perfectas son aquellos seres humanos que todo el tiempo han sido usados como medios para que el poder dominante, a través del fetiche, sea cada vez más poderoso (Dussel, 2016). 
Así, si el fetiche representa al Baal cananeo, Moloch, que es el mismo capital, que es el dios de los luteranos ortodoxos, de algunos católicos y del pueblo judío, entonces sí sería posible tildar a Marx de ateo. De ahí lo que sostiene Dussel:

Marx hubiera podido afirmar, con Justino, lo que este escribió en el siglo II contra los grupos hegemónicos del imperio romano: "De ahí que se nos ponga también el nombre de ateos (á- theoi). Si de esos supuestos dioses [romanos] se trata, confesamos ser ateos (átheoi éinai)". (Dussel, 1993, p. 16)

Es ese fetiche el que evita que el ser humano se emancipe y encuentre el rigor y verdadero sentido de su vida y de su trascendencia en la cotidianidad y en el encuentro con otros. Algo difícil de lograr, dadas las condiciones de los habitantes de las regiones donde Moloch era

profundamente adorado y justificado bajo argumentos judíos y judeocristianos. De esto comenta Marx de su país natal: "Por eso Alemania se encontrará un día al nivel de la decadencia europea sin haber alcanzado nunca el de la emancipación europea. Será como un prosélito del fetichismo que perece por las enfermedades del cristianismo". (Groni en Marx, 2012b, p. 56)

Moloch, el dios del capital, o mejor, el capital mismo, es el plusvalor acumulado (Gómez, 2015), objetivación del trabajo impago. El campesino es su propósito y su medio, necesario para ordenar el sistema y hacer creer que quienes lo integran reciben compensación. Así, aquel, convertido en obrero, termina rindiéndole culto con su esfuerzo y asimismo retribuido con parte de lo que él mismo está ofreciendo (Dussel, 1987). De esta forma también se da una contradicción con el Dios verdadero, quien lo primero que rechaza es la concepción retributiva que en algún momento se tuvo de Él, que es totalmente ajena a su verdadera presencia y significado.

En sus Grundrisse (anotaciones) hablando del dinero Marx expresa, según transmite Dussel: "De su figura de siervo (Knechtsgestalt), en la que se presenta como simple medio de circulación, se vuelve de improviso soberano y dios del mundo de las mercancías" (1993, p. 19).

El texto anterior dice prácticamente lo contrario a lo que presenta san Pablo en el himno cristológico de su Carta a los filipenses: 
Cristo, siendo de condición divina no hizo alarde de su categoría de Dios, por el contrario, se anonadó a sí mismo pasando por la condición de esclavo y así, actuando como un hombre cualquiera, se sometió a una muerte, una muerte de cruz. (Flp 2:6-8)

El verdadero Dios deja su condición divina para hacerse esclavo de todos, mientras el fetiche que es el capital pasa de ser siervo a convertirse en una entidad divina. El primero se entrega de manera gratuita y no pide algo a cambio, mientras que el segundo exige un sacrificio constante del proletariado para que ofrende su trabajo, que no es otra cosa que su vida misma, tal como muchos pueblos ofrecían sacrificios humanos para obtener un favor de su deidad. Nuevamente aparece el fetiche demandando que se inmolen vidas en su nombre con el fin de tranquilizarlo y estabilizarlo. Se justifica una vez más la violencia enmascarada en lo sagrado. El verdadero Cristo se enfrenta así con el anticristo: “Aquel se humilló, bajó; el dinero sube, se diviniza” (Dussel, 1993, p. 19).

Las personas que hacen parte del proletariado no tienen escapatoria ante el fetiche. Este los domina y los manipula para que permanezcan en su dinámica de oblación. Cada quien, como parte de la comunidad sacrificial, tiene que seguir rindiendo culto a partir del aumento del capital divinizado, engrandecido para que siga beneficiando a sus súbditos a su manera (Ranciere, 2010, p. 113).

La crítica central de Marx es la imposibilidad de salir de ese círculo alienante que no deja escapar a nadie pues, aunque el fetiche es una hechura humana, no puede mantenerse si no hay voluntarios que mantengan ese poder identificado como divino y sagrado. Pero esa situación puede cambiar si el mismo proletariado busca emanciparse (Marx, 2012a, p. 62).

El fetichismo es el medio alienante en una sociedad sobre todo cuando justifica su violencia a partir de lo sagrado. En este caso, se derrota a la humanidad misma haciéndola creer que aquel es un sacrificio necesario, y así se justifica su ordenamiento dentro de un Estado. Pero Marx sabe muy bien que el hombre para alcanzar su realización plena debe construir algo común, tal como el modelo del cristianismo primitivo, por lo que expone: "Tan sólo en el socialismo puede un pueblo filosófico encontrar su práctica adecuada, y únicamente en el proletariado puede hallar el elemento activo de su liberación” (Marx, 2012a, p. 81). 
Ante las injusticias atestiguadas, la mayor esperanza de Marx — que veía cómo en su nación, al igual que en toda Europa, se estaba replicando ese fetichismo-, era que ese pueblo adormecido se despertara. Por ese motivo su postura va a resultar muy similar a la teología de la liberación, que surgiría más tarde en Latinoamérica. Así lo percibe Dussel en el pensamiento del alemán: "No fue, en el sentido estricto del término, un teólogo. Abrió el horizonte para una nueva teología, lo que es muy diferente" (Dussel, 1993, p. 18).

Es correcto sostener que la búsqueda incansable de Marx es por el ascenso del proletariado para romper con su dependencia de ese dios falso, el fetiche. Sería errado pensar que estaba contemplando una teología de la liberación. Sin embargo, sí podría ser un acierto comprender que referirse al capital como un fetiche que deshumaniza al ser humano (Núñez, 2009, p. 38) ilustra cómo este debe romper con Moloch y Mammon, deidades que buscan arrastrarlo hacia su ceguera deshumanizante y esclavizadora. Esa lucha contra tales figuras demoniacas va a ser la misma que dará en Latinoamérica la teología de la liberación dado que también aquí se sembró el terror a través de esos mismos dioses paganos representados en el capital. Con ese tema se finiquitará la reflexión presente.

\section{Hacia una anamnesis de la teología de la liberación}

Una anamnesis de la teología de la liberación responde a la necesidad de rememorar las reacción de un pueblo cristiano que veía en el verdadero rostro de Jesús, en su vida entregada a la lucha por los marginados y vulnerables, una salida a la opresión y la injusticia surgidas de los nuevos fetiches que estaban aplastando la humanidad de todos (Berryman, 1989, p. 17).

El dolor por tantas injusticias y sufrimientos clama una respuesta del mismo Dios de Israel, que se había acordado de su pueblo cuando estaba en Egipto. Solo los dioses falsos llevan a que unos pocos se sientan fuertes y seguros de la opresión que pueden ejercer contra los desvalidos, pobres, explotados y acabados. Por el contrario, Yahveh es el dios que salva, que libera y que puede restaurar la dignidad arrebatada por el fetiche de los altos dominadores:

Yahveh se presenta abiertamente y sin subterfugios: es el Dios verdadero por ser el Dios de la liberación. Su manifestación por excelencia fue en la lucha 
contra el faraón en Egipto. Pero, ¿quién es Baal y por qué aparece en la tradición como el archienemigo de Yahveh? Es lógico suponer que el enemigo del Dios de la liberación sea el dios que legitima la dominación. Y veremos más adelante que Baal fue efectivamente el dios de los dominadores. (Dussel, 1993, p. 35)

Es la experiencia con ese Yahveh la que se reclama desde el suelo latinoamericano, donde el encuentro real con Jesús invita a la corresponsabilidad, a hacerse uno con toda la creación (Francisco, 2015), pues aquí el fetiche incluso exige el sacrificio del medio ambiente en su nombre. El capital es despiadado, quienes lo administran también se muestran así, y el capitalismo se aprovecha al máximo para cosificar al sujeto. Este ya no tiene derechos, sino deberes y obligaciones con un nuevo señor feudal del siglo xxi que tiene el objetivo de hacer valer su posición dominionista de la realidad y de la relación capitalista-proletariado (Echeverría, 1995, p. 7).

Pero el cristiano que es consciente del Dios verdadero sabe muy bien cómo clamar al cielo sin apartarse de la realidad tanto suya como de quienes comparten la misma desgracia. Es más, cuando existe una debida experiencia con el creador de todo, se da dentro de ese grupo de hombres una conciencia emancipadora bajo la cual buscan restablecer el orden dañado por el fetiche. Dicha conciencia emancipadora pudo haberla tenido Marx, quien de seguro, junto con el salmista, entendía y conocía la mentira detrás de los baales del poder dominante, que se refleja en el salmo 115 (4-7):

Sus ídolos son plata y oro,

hechura de manos humanas.

Tienen boca y no hablan,

tienen ojos y no ven,

tienen orejas y no oyen,

tienen nariz y no huelen,

tienen manos y no tocan,

tienen pies y no andan.

El capitalismo agresivo y caníbal que surgió en América Latina producto de poderes dominantes como los de EE. UU. y algunos imperios de Europa dejó ver claramente cómo el ser humano pasó a un segundo plano sin la posibilidad de cambiar el sistema. En efecto, la dominación no solo se dio imponiendo un nuevo sistema de control económico, sino que hubo acuerdos con los mismos gobiernos de la región para que 
mantuvieran la nueva estructura implantada. El pretexto fue una aparente vida en libertad, cuando la única libertad la tienen quienes son dueños del capital, del fetiche. Así, escribe Dussel:

\begin{abstract}
Marx retorna la palabra y el concepto "fetiche" — del portugués fetiço: "hecho" de la mano del hombre- en su discurso teórico esencial posterior, por adecuarse dicho concepto de fetiche a un doble proceso: ser fruto del trabajo del hombre, objetivación de su vida, y constitución de dicha objetivación como un poder autónomo extranjero, ajeno. (Dussel, 1993, pp. 40-41)
\end{abstract}

No solo el fetiche es producto de unos hombres que lo inventan, tal como lo presenta el Salmo 115, sino que es alimentado por ellos, que lo ponen así con una personificación propia, aun sabiendo que es manejado por unos poderes directos. De igual forma, va a adquirir una figura divina y sagrada. Este fetiche debe ser puesto en el lugar que corresponde, el de medio, debe tener una transformación, de tal manera que pierda la dimensión sacra en la que se le ha puesto. De lo contrario será sinónimo de muerte porque acabará con el propio trabajo de la persona que labora, y seguidamente, con la vida de toda la comunidad, razón de ser del trabajador y de una sociedad. Dussel sostiene de Marx:

Desde sus primeros estudios económicos, Marx descubre la esencia alienada del trabajo como muerte del trabajador y producción por sus propias manos de su opuesto, su enemigo, el fetiche, como sacrificio:

“[...] El capital muerto (tote) va siempre al mismo paso y es indiferente a la real actividad individual [...] El obrero sufre en su existencia y el capitalismo en la ganancia de su Mammón muerto (toten Mammons)”. “[...] solo mediante el sacrificio (Aufopferung) de su cuerpo y de su espíritu (del obrero) puede saciarse [...]". "El objeto que el trabajo produce, su producto, se enfrenta a él como un ser extraño, como un poder (Macht) independiente del productor. El producto del trabajo es el trabajo que se ha fijado en un objeto, que se ha hecho cósico (sachlich)". (Dussel, 1993, p. 48)

Todo ese peso dominante se presenta como causal del daño que se ha introducido en la sociedad para regular las relaciones sociales alienándolas mediante el fetiche, el 
capital. De ahí surge la crítica ante tales sistemas, que no buscan sino acabar con la sociedad, las comunidades, las familias y, finalmente, el trabajador como individuo.

Al igual que Jesús, Marx y la teología de la liberación buscan la instauración de la justicia real en la tierra, en la historia. Comparten pues la aspiración de Thomas Müntzer, reformador alemán durante las guerras campesinas, y del pietismo, opuesta a concepciones como la del luteranismo ortodoxo, que solo aspiran a la justicia después de la muerte.

La encarnación del Hijo de Dios debe ser la muestra fehaciente de la historicidad del mismo creador. Yahveh no puede ser apáthico a las diferentes circunstancias por las que atraviesa el ser humano, no puede ser indiferente ante estas. Por eso siempre se presenta en el texto sagrado como un dios que sigue escuchando el clamor de los que sufren a causa de las injusticias. Y por eso el Reino de los Cielos, no puede ser el del Oủpavóc/uranós, sino el que busca darle a cada quien lo que le corresponde, es decir, aquel que se entiende a partir de valores cristianos como la dignidad humana, la libertad y la justicia. Solo la materialización de estos tres grandes principios puede reestablecer la relación humanidad-creador, fracturada debido a la intromisión y la enajenación ocasionadas por el fetiche.

La teología de la liberación, por tanto, ha llamado a instaurar ese reinado de Dios en la tierra con el fin de hacer a un lado todo lo opuesto al mensaje de Jesucristo. Al fin y al cabo la explotación de todo cuanto existe conlleva mantener a Molloch y a Mammon vivos:

El culto al dinero (Geldkultus) tiene su ascetismo, sus renuncias y sus sacrificios la frugalidad y la paciencia [...]. De aquí deriva la conexión del puritanismo inglés o también protestantismo holandés con la tendencia a acumular dinero.

(Dussel, 1993, p. 69)

Lo descrito hasta aquí se sigue repitiendo en la actualidad. Y aunque parezca arriesgado afirmarlo, también hay quienes siguen esperando una intervención directa de Dios a través de rayos y centellas, que restablezca el orden de modo diluviano para ver la creación entera renovada y exenta de todo vicio; que el "Todopoderoso" se haga presente salvando a los buenos y condenando a los malos. Algo que seguramente no va a suceder puesto que el poder de Dios se halla precisamente en la humanidad de 
cada hombre y mujer, que pueden lograr la emancipación del mundo enajenado por el fetiche del dinero. La única condición es unir fuerzas para conformar una nueva comunidad humana donde cada quien reconozca su esencia de solidaridad y corresponsabilidad. De lo contrario, cada uno seguirá siendo parte del mismo sistema impositivo y desnaturalizador.

La teología de la liberación hace un llamado para que tanto la teología como la filosofía dispongan sus saberes en pro de la emancipación humana. Tal como lo presenta Dussel a propósito de Marx, para quien la historia, la filosofía y la teología se relacionan íntimamente en el pensamiento crítico: "La tarea de la historia consiste en establecer el más acá de la verdad después de haber desvanecido el más allá de la verdad" (Dussel, 2017).

Se trata de una teología controvertida, que hace eco de un cristianismo mesiánico, el mismo de los primeros cristianos, que buscaron actuar de la manera más humana posible. El mismo cristianismo que surgió a partir de enseñanzas del Maestro de Nazareth como las proclamadas a través de las bienaventuranzas, que tienen presentes siempre primero a los pobres, los marginados.

Ahora bien, incluso en nuestro contexto de violencia ese cristianismo mesiánico es el que llama a la humanidad a hacerse parte de la esperanza a partir de acciones de inclusión en pro de los menos favorecidos o los que han sufrido constantemente. Como las víctimas de actos atroces, que necesitan no solo una voz de aliento, sino recuperar su integridad y sus derechos, lo cual se puede dar mediante la memoria como parte del restablecimiento de una justicia histórica (Lois, 1986, p. 5). La misma que ha estado en manos de los victimarios, tal cual sucede con el capital cuando termina en manos del poder dominante y de ese cristianismo invertido, dándole paso así al fetiche.

Así, se puede sostener que el fetiche de esta época es la injusticia vestida de justicia y llena de impunidad, que todo lo justifica y cree que el olvido es la mejor forma de hacerle el debido trato a las víctimas. Pero eso lo único que ocasiona es una herida más grande, revictimizándolas y convirtiéndolas en medios en lugar de fines. Dice Dussel (2017):

El método de los profetas de Israel consistía en situarse en el lugar de los pobres y desde allí hacer el diagnóstico de la patología del Estado. 
Hay que situarse en el lugar de los oprimidos, de las víctimas y desde allí hacer un diagnóstico de la patología del Estado.

De esa manera, Dussel enuncia la necesidad de una anamnesis de la teología de la liberación, que siga persiguiendo instaurar el Reino de Dios en la tierra, que sea la voz de los que son silenciados, la expresión sin barreras de los que no tienen libertad y el grito de reclamo de aquellos que siguen siendo enajenados por la pasividad de quienes ostentan el poder para restablecer sus derechos (Boff, 2015). La teología debe ser pues un espacio que no renuncie a la contemplación, sino que como consecuencia de esta decida una intervención emancipatoria en la historia, tal como la del padre de la Orden de Predicadores, Domingo de Guzmán: Contemplari et aliis tradere contemplata (“Contemplar y llevar a los demás lo contemplado"). Fruto de la oración se da la intervención en la historia debido a que Dios no es ahistórico ni apático, todo lo contrario, se ha hecho carne y ha puesto su morada entre nosotros (Jn 1:14).

La palabra que no deja de meditar y poner por escrito Marx es emancipación: acción que busca llevar al ser humano a un estado de cambio, de transformación de menos humano a humano, de ser explotado a ser libre y administrador autónomo del propio capital.

La crítica de Marx no es contra la religión, ni mucho menos contra el cristianismo, sino contra el fetichismo y el cristianismo invertido, dos fenómenos que llevan a los más vulnerables a un plano netamente utilitarista que sacrifica todas sus fuerzas para obtener valor material. Este termina así siendo superior al mismo hombre, razón por la que se da una crítica constante y un llamado a la teología para que no desdiga lo que ya Cristo había expresado a través de sus palabras y sus hechos. El propósito es el restablecimiento de la relación entre Dios y el hombre solamente posible mediante la amistad entre los mismos seres humanos.

Volver a la teología de la liberación es recordar las palabras de aquel tercer domingo de adviento de 1511 de Fray Antonio de Montesinos, O. P., cuando denunció: “¿Aquestos no son hombres? ¿No tienen animas racionales?”.

Esta teología busca así recuperar la esencia humana para que cada hombre vuelva a estar en la cumbre de la creación, no como dominador del universo, sino como colaborador de la realización humana y como agente fraterno de la misma naturaleza. 


\section{Referencias}

Berryman, P. (1989). Teología de la liberación. México: Siglo XXI.

Boff, L. (2015). El papa Francisco y la teología de la liberación. Feadulta.com. Recuperado de https://tinyurl.com/y3u9w9zw

Casabó, J. (2007). Esclavitud y cristianismo. Biblio3W. Revista Bibliográfica de Geografía y Ciencias Sociales, 12. Recuperado de http://www.ub.edu/geocrit/ b3w-758.htm

Cueva, A. (1984). El fetichismo de la hegemonía y el imperialismo. Cuadernos Políticos, 38, 31-39.

Dussel, E. (1977). Religión, Enrique Dussel. Textos completos. México: Edicol.

Dussel, E. (1987). Clase obrera e Iglesia en América Latina. Revista Mexicana de Sociología, 49(3), 145-150.

Dussel, E. (1993). Las metáforas teológicas de Marx. México: Siglo XXI.

Dussel, E. (2015). Dossier: San Romero de América. La religión como crítica a la opresión. La figura mesiánica de Óscar Arnulfo Romero (1917-1980). Tareas, $151,113-117$.

Dussel, E. (2016, 15 de noviembre). La importancia de entender los mitos [Video]. Recuperado de https://www.youtube.com/watch?v=-ylf1TeI7rg

Dussel, E. (2017, 15 de junio). El diálogo interreligioso [Video].México: СeIICH, Unam. Recuperado de https://tinyurl.com/y2a9wytz

Echeverría, A. B. (1995). Modernidad y capitalismo (15 tesis). Recuperado de https:// tinyurl.com/yyrfbv97

Francisco (santo padre) (24 de mayo de 2015). Laudato si'. Santa Sede: Tipografía Vaticana. Recuperado de https://tinyurl.com/ncnkttm

Gómez, A. (24 de noviembre de 2015). Moloch y el culto a la riqueza. El Asunto Urbano. Recuperado de https://tinyurl.com/y3e99b5z

Lois, J. (1986). Teología de la liberación. Opción por los pobres. Madrid: Iepala. 
Marx, K. (2012a). Contra el Estado: glosas críticas marginales al artículo "El rey de Prusia y la reforma social. Por un prusiano”. En Sobre la cuestión judía y otros textos (pp. 67-90). Buenos Aires: Anarres.

Marx, K. (2012b). Para una crítica de la filosofía del derecho de Hegel. Introducción. En Sobre la cuestión judía y otros textos (pp. 47-60). Buenos Aires: Anarres.

Marx, K. (2012c). Sobre la cuestión judía y otros textos. Buenos Aires: Anarres.

Núñez, A. (2009). De la alienación al derecho a la ciudad. Una lectura (posible) sobre Henri Lefebvre. Theomai, 20, 34-48.

Ranciere, J. (2010). La noche de los proletarios. Buenos Aires: Tinta Limón.

Romero, A. (2005). Teoría económica y ciencias sociales: alienación, fetichismo, colonización. Apuntes, 56/57, 115-138.

Spadaro, A. (2017, 18 de agosto). Fundamentalismo evangélico e integrismo católico. Un ecumenismo sorprendente. Civiltá Cattolica Iberoamericana [Blog]. Recuperado de https://tinyurl.com/y3hfylhr

Strom, C. (2019, 12 de febrero). Un dios terrible que exigía sacrificios de niños: origen y naturaleza del culto a Moloch. En www.ancient-origins.es. Recuperado de https://tinyurl.com/y5nnd8dg

Weber. M. (1991). La ética protestante y el espíritu del capitalismo. México: Premia. Recuperado de https://tinyurl.com/yx2mdft4

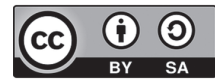

